\title{
BOLOGNA'S PROCESS, GRADUATION, AND POST-MODERNITY: ANALYZING THE MANAGEMENT IN THE BIOLOGICAL SCIENCES 2 COMITEE FROM CAPES AGENCY
}

\author{
Silva, R.R., Zingali, R.B
}

IBqM, UFRJ, Rio de Janeiro-RJ.

This work is a comparative qualitative study focusing on Brazilian and European models of educational management in graduate programs. Among the issues discussed, we draw upon strategic policies developed by the coordinators of masters and doctoral programs that are included in and managed by the Biological Sciences II Commitee from the Coordination for the Advancement of Higher Education Personnel (CAPES). Our approach is made within the theoretical framework of Lyotardian postmodernity, and we consider the constraints imposed by today's science in terms of assumptions and focus on productivity. Our methodological approach consists of semi-structured interviews with coordinators of undergraduate programs and policy makers involved in implementing the Bologna Process. Our analysis points to significant convergences between Bologna's agenda and the Brazilian model of graduate programs. However, the recent results of the assessment of Brazilian graduate programs conducted by CAPES may hide a demand for policies at the macro level, i.e., governmental policies, rather than for local policies, i.e., particular to graduate courses. This hidden demand would address the problem of these courses' focusing on quantity, rather than quality, which is an issue to be discussed from the postmodern Lyotardian's perspective. 